\title{
STATUS OF PRECIPITATION HARDENED NICKEL BASE ALLOYS INCLUDING 718 FOR OILFIELD APPLICATIONS
}

\author{
Robert P. Badrak \\ Weatherford \\ 11909 FM 529 \\ Houston, Texas, 77041 \\ USA
}

\begin{abstract}
Keywords: nickel alloys, precipitation hardening, 718, oilfield, fatigue, corrosion, environmental cracking, drilling, completion, oil production
\end{abstract}

\begin{abstract}
This paper describes typical upstream oilfield applications for 718 and similar precipitation hardened nickel base alloys. These include products in the drilling, completion and production segments of the upstream market. The discussion of applications is accompanied with current understanding of the limitations and regulations affecting applications of these alloys. A contrast is presented between the precipitation hardenable and cold worked nickel alloys with respect to applications and performance limitations.
\end{abstract}

The different market segments with the relevant applications exhibit different failure mechanisms. A discussion is presented that illustrates where the various failure mechanisms are found and the factors that have been identified that affect the risk of occurrence. Some metallurgical factors that we know affect the susceptibility of these alloys to the failure mechanisms are presented.

The last subject discussed is the future with respect to these alloys. The expected changes in the operating conditions and applications are identified with the associated hurdles that will need to be overcome. These projections provide some direction to the Oil \& Gas Industry and the alloy manufacturers that supply them.

\section{Introduction}

There are many nickel base alloys used today in the Oil \& Gas Industry. The author knows of use with 718 dating as far back as at least the late 1970's. The alloys in use today are both hardened through cold work and precipitation hardening. The more common alloys are listed in Tables 1 and 2 for cold worked and precipitation hardened alloys respectively. The cold worked alloys find most of their applications (by tonnage) in the form of tubular products. A 1996 survey conducted by a NACE Committee ${ }^{1}$ revealed that the cold worked nickel base alloys accounted for a little over $10 \%$ of all the corrosion resistant alloy tubulars. All of these nickel base alloys were identified as cold worked alloys and the average quantity per year was approximately 45,000 meters/year during the period $1985-1993$. 


\begin{tabular}{|c|c|c|c|c|c|c|c|c|c|c|}
\hline \multicolumn{10}{|c|}{ Table 1: Nominal Compositions of Solid Solution Hardened Nickel Base Alloys } \\
\hline type & name & UNS & $\mathrm{Ni}$ & $\mathrm{Cr}$ & $\mathrm{Fe}$ & $\mathrm{Mo}$ & $\mathrm{Ti}$ & $\mathrm{Cu}$ & $\mathrm{Nb}+\mathrm{Ta}$ & other \\
\hline $3 \mathrm{Mo}$ & 28 & $\mathrm{~N} 08020$ & $35 \%$ & $20.5 \%$ & $40 \%$ & $2.5 \%$ & --- & $3.5 \%$ & --- & --- \\
\hline $3 \mathrm{Mo}$ & 825 & $\mathrm{~N} 08825$ & $42 \%$ & $21.5 \%$ & $28 \%$ & $3 \%$ & $1 \%$ & $2.2 \%$ & --- & --- \\
\hline $3 \mathrm{Mo}$ & 2535 & $\mathrm{~N} 08535$ & $33 \%$ & $25.5 \%$ & $36 \%$ & $3.2 \%$ & --- & --- & --- & --- \\
\hline $6 \mathrm{Mo}$ & $\mathrm{G} 2$ & $\mathrm{~N} 06975$ & $49 \%$ & $24.5 \%$ & $18 \%$ & $6 \%$ & $1 \%$ & $1 \%$ & --- & --- \\
\hline $6 \mathrm{Mo}$ & $\mathrm{G} 3$ & $\mathrm{~N} 06985$ & $46 \%$ & $22.5 \%$ & $20 \%$ & $7 \%$ & -- & $2 \%$ & --- & --- \\
\hline $6 \mathrm{Mo}$ & 42 & $\mathrm{~N} 08042$ & $41 \%$ & $21.5 \%$ & $26 \%$ & $6 \%$ & $1 \%$ & $2.2 \%$ & --- & --- \\
\hline $6 \mathrm{Mo}$ & 2550 & $\mathrm{~N} 06255$ & $50 \%$ & $24.5 \%$ & $20 \%$ & $7 \%$ & --- & --- & --- & --- \\
\hline $9 \mathrm{Mo}$ & 625 & $\mathrm{~N} 06625$ & $64 \%$ & $21.5 \%$ & $2 \%$ & $9 \%$ & --- & --- & $3.5 \%$ & --- \\
\hline $9 \mathrm{Mo}$ & $\mathrm{G} 50$ & $\mathrm{~N} 06950$ & $52 \%$ & $20 \%$ & $18 \%$ & $9 \%$ & --- & --- & --- & --- \\
\hline $16 \mathrm{Mo}$ & $\mathrm{C} 276$ & $\mathrm{~N} 10276$ & $58 \%$ & $15.5 \%$ & $5 \%$ & $16 \%$ & --- & --- & --- & $4 \% \mathrm{~W}$ \\
\hline \multicolumn{19}{|c|}{ Note $1:$ iron content is estimated } & & & \\
\hline
\end{tabular}

\begin{tabular}{|c|c|c|c|c|c|c|c|c|c|c|}
\hline \multicolumn{10}{|c|}{ Table 2: Nominal Compositions of Precipitation Hardened Nickel Base Alloys } \\
\hline type & name & UNS & $\mathrm{Ni}$ & $\mathrm{Cr}$ & $\mathrm{Fe}$ & $\mathrm{Mo}$ & $\mathrm{Ti}$ & $\mathrm{Al}$ & $\mathrm{Cu}$ & $\mathrm{Nb}+\mathrm{Ta}$ \\
\hline 3Mo & 718 & $\mathrm{~N} 07718$ & $52 \%$ & $19 \%$ & $19 \%$ & $3 \%$ & $1 \%$ & $0.5 \%$ & --- & $5 \%$ \\
\hline $3 \mathrm{Mo}$ & 925 & $\mathrm{~N} 09925$ & $44 \%$ & $21.5 \%$ & $26 \%$ & $3 \%$ & $2.2 \%$ & $0.3 \%$ & $2.2 \%$ & --- \\
\hline $3 \mathrm{Mo}$ & 935 & $\mathrm{~N} 09935$ & $36 \%$ & $21 \%$ & $34 \%$ & $4 \%$ & $2.2 \%$ & --- & $1.5 \%$ & $0.6 \%$ \\
\hline $3 \mathrm{Mo}$ & 945 & $\mathrm{~N} 09945$ & $47 \%$ & $21.5 \%$ & $20 \%$ & $3.3 \%$ & 1.5 & $0.3 \%$ & $2.2 \%$ & $3.2 \%$ \\
\hline 9Mo & 725 & $\mathrm{~N} 07725$ & $57 \%$ & $20.5 \%$ & $8 \%$ & $8.2 \%$ & $1.4 \%$ & --- & --- & $3.4 \%$ \\
\hline 9Mo & $625+$ & $\mathrm{N} 07716$ & $61 \%$ & $20.5 \%$ & $4 \%$ & $8.2 \%$ & $1.3 \%$ & --- & --- & $3.4 \%$ \\
\hline \multicolumn{11}{|c|}{ Note 1: iron content is estimated } \\
\hline
\end{tabular}

The characteristics of nickel base alloys that have resulted in numerous oilfield applications include a combination of a high strength level coupled with corrosion and environmental cracking resistance in oil and gas wells. One feature of the Oil \& Gas Industry is that most designs are based on $0.2 \%$ offset yield strength. The minimum strength level considered usable or acceptable for nickel based alloy applications is typically $760 \mathrm{MPa}(110 \mathrm{ksi})$ yield strength with certain grades having minimum yield strength levels often exceeding $1035 \mathrm{MPa}$ (150 ksi).

All of the alloys in Tables 1 and 2 meet the $760 \mathrm{MPa}(110 \mathrm{ksi})$ minimum yield strength required. The precipitation hardening alloys that are capable of achieving higher minimum yield strength levels include UNS N07725 alloy at $896 \mathrm{MPa}$ (130 ksi), UNS N09945 at $965 \mathrm{MPa}$ (140 ksi) and UNS N07718 and UNS N07716 at $1034 \mathrm{MPa}$ (150 ksi).

The drive to use precipitation hardened nickel base alloys originated in applications for products that could not be reasonably made from cold work alloys because of the section sizes and historical limitations on driving the cold work to meet requirements. Many of the applications are machined from bar stock or forged with the bar stock route as the most common manufacturing process because of geometry and lot size constraints. This paper primarily pertains to precipitation hardened nickel base alloys.

In very rough terms, the Oil \& Gas Industry characterizes the nickel base alloys in terms of application envelope - the ability to withstand the environmental conditions inherent in the application. The major conditions considered relevant include temperature, $\mathrm{H}_{2} \mathrm{~S}$ partial pressure, $\mathrm{CO}_{2}$ partial pressure, chlorides and the presence of oxidants such as oxygen and elemental sulfur. The relationship between specific alloys (and composition) with environmental envelopes is 
defined in NACE MR0175/ISO $15156^{2}$. The key elemental constituents listed are usually defined as molybdenum and chromium. To simplify the variables is a little risky in that there are exceptions to the rules but we as an industry have informally used the criteria of molybdenum content to differentiate these alloys; the most common being a nominal 3\% Mo alloy followed by $6 \% \mathrm{Mo}, 9 \% \mathrm{Mo}$ and $16 \%$ Mo containing alloys. This generalization applies to both cold worked alloys and precipitation hardened nickel base alloys. The common nickel base alloys are grouped in Tables 1 and 2 by nominal molybdenum content. The performance envelopes that define corrosion resistance and maximum safe use temperature that we develop are primarily correlated to molybdenum content.

The Oil \& Gas Industry is broadly classified as upstream (from exploration through the wellhead) and downstream (beyond the wellhead into piping and eventually refining and service gas). This paper addresses only the upstream side of the business. The upstream business can be further broken down into the exploration, drilling, completion and production segments. These segments have requirements for nickel base alloys that have both similarities and differences. The production and completion segments are similar enough that they are covered here together. The same is true for the exploration and drilling segments and they are also covered together.

What is similar between these segments are the basic requirements of high strength level coupled with corrosion and environmental cracking resistance. The differences are the levels of strength and environmental cracking/corrosion resistance along with more targeted properties to address specific failure modes such as high temperature strength or fatigue resistance.

\section{Drilling and Exploration}

In the drilling segment of the business, stresses are cyclical (rotating bending stresses often combined with tensile and burst or collapse stresses). Stress concentrations due to operation and design take on a much more significant role in the presence of these cyclical stresses. The tools that operate in this segment are additionally often subjected to vibrational stresses including harmonics.

The environment is predominantly drilling fluids but often the fluids are contaminated or comingled with production fluids and weighting fluids such as brines. The drilling fluids themselves are often corrosive due to high chloride contents and oxygen. Though austenitic (non-magnetic) stainless steels are often used, these often have insufficient corrosion and environmental cracking resistance and nickel base alloys, primarily 718 , are used.

The common tool applications that utilize nickel alloys in this business segment include Wireline equipment, MWD (Measurement While Drilling), LWD (Logging While Drilling) and critical high stressed components of the BHA (Bottom Hole Assembly). The Wireline equipment is defined as a variety of tools that are used to perform numerous functions in a well (usually during the exploration or drilling process) and is characterized by being run in and run out of the well on a wireline. Here the wireline provides the means of conveyance as well as communication and power to the tools being operated on the end of the wire rope. Figure 1 depicts some of this equipment for a BHA that is used for rotary steering. The total length of the depicted BHA is in the range of about 43 meters ( $140 \mathrm{ft}$ ) with many of the components listed being manufactured from nickel based alloys. 
$83 \mathrm{At}$

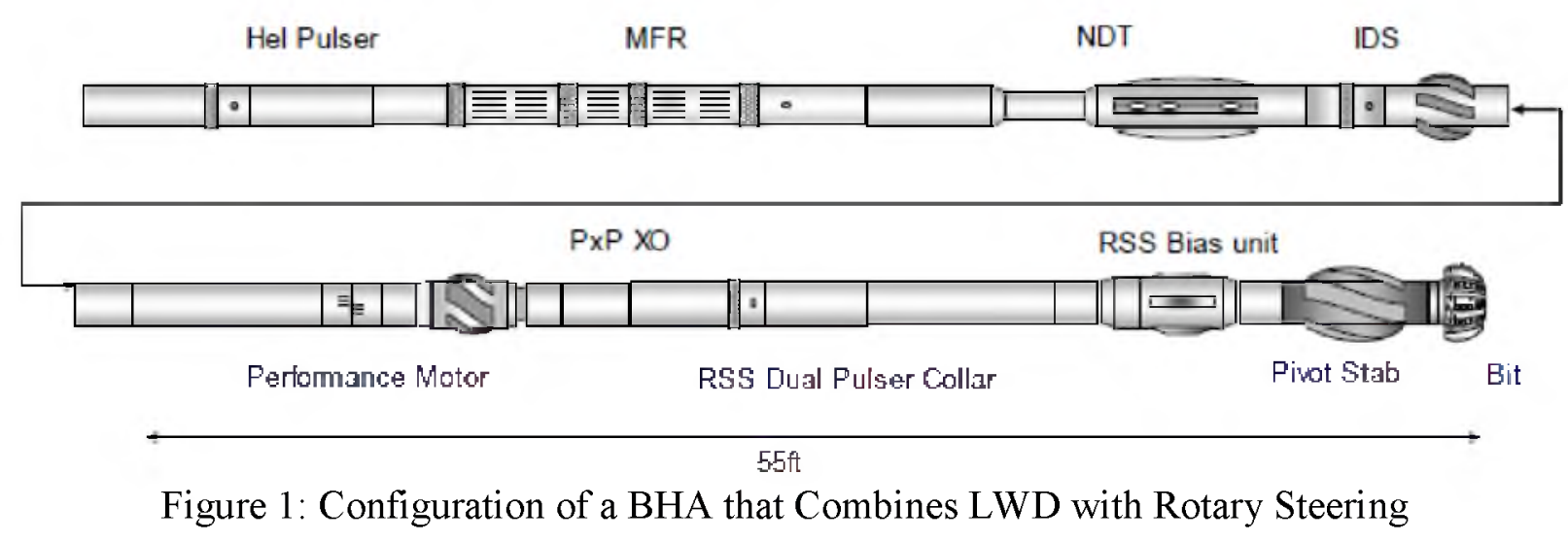

Though other nickel base alloys find small niches in this market segment, the majority of the applications use 718 . The desirable characteristics of the alloy (718) are yield strength levels that are usually above $1035 \mathrm{MPa}(150 \mathrm{ksi})$ with good fatigue resistance and fracture toughness. The typical application temperature range is $65^{\circ} \mathrm{C}-175^{\circ} \mathrm{C}\left(150^{\circ} \mathrm{F}-350^{\circ} \mathrm{F}\right)$ and the temperature is usually not the limiting factor in this market segment for nickel base alloys. Because of the lower temperature range and, usually, limited contact with harsh production fluids, the more extreme requirements that are imposed on 718 for completion and production segments are not imposed here.

\section{Completion and Production}

In the completion and production segments of the business, stresses are usually static but stress cycles can result from vibrations/harmonics as well as those related to thermal changes. The contacting fluids can be as variable as the production environments and also the result of injected fluids to stimulate or assist the production of hydrocarbons. The environments and requirements between injection/stimulation and production applications are different and, often, equipment needs to function in both because of alternating injection and production cycles.

The production fluids are anaerobic but often contain the acid gases carbon dioxide and hydrogen sulfide, organic acids and sodium chloride salt with varying water contents that usually increase as the formations are drawn down (produced). The injection fluids may contain some oxygen and could be composed of natural gas, carbon dioxide, fresh water, brackish water, salt water, or produced water. The stimulation fluids could be a variety of materials but often contain high percentages of hydrochloric acid and, occasionally, hydrofluoric acid. It is also common practice to use high concentration salts (brines) in the annulus (space between the tubing and the casing walls) to prevent acid gas solubility as a safety precaution. These brines in themselves need to be considered in the materials selection process when encountered.

The temperature can range from ambient for shut-in (not producing) surface or subsea equipment to the bottom hole temperature. The trend for the temperature and total system pressure is to increase with increasing depth beneath the surface. In this manner the deepest wells exhibit the highest pressures and temperatures. The bottom hole temperature range that covers most applications is typically $85^{\circ} \mathrm{C}-232^{\circ} \mathrm{C}\left(185^{\circ} \mathrm{F}-450^{\circ} \mathrm{F}\right)$. The combination of the environment with the temperature range often dictates that corrosion resistant alloys are used with most of the 
severe applications requiring nickel base alloys for the products that contact produced or injected fluids.

As a generalization, tubular products (termed OCTG or Oil Country Tubular Goods) are typically made from cold worked nickel base alloys when nickel based alloys are required. For accessories and equipment that are made from bar, cast or forged products, the precipitation hardened nickel based alloys are typically used. The minimum strength levels are typically at least $760 \mathrm{MPa}(110 \mathrm{ksi})$ yield strength for subsurface equipment but there is some use of lower strength levels including $500 \mathrm{MPa}$ (75 ksi) minimum yield strength equipment at the surface. With HPHT (High Pressure High Temperature) applications there has been a drive over the last few years for higher yield strength levels including $940 \mathrm{MPa}(140 \mathrm{ksi})$.

The common tool applications in this business segment are packers, flow control devices, safety valves, sand control equipment, tubing and casing hangers, artificial lift equipment and wellhead equipment. Figure 2 depicts one down hole configuration of completion equipment including packers that are used to isolate different production zones, often from aquifers, and sand screen sections which are used to filter out sand particles from the production fluids.

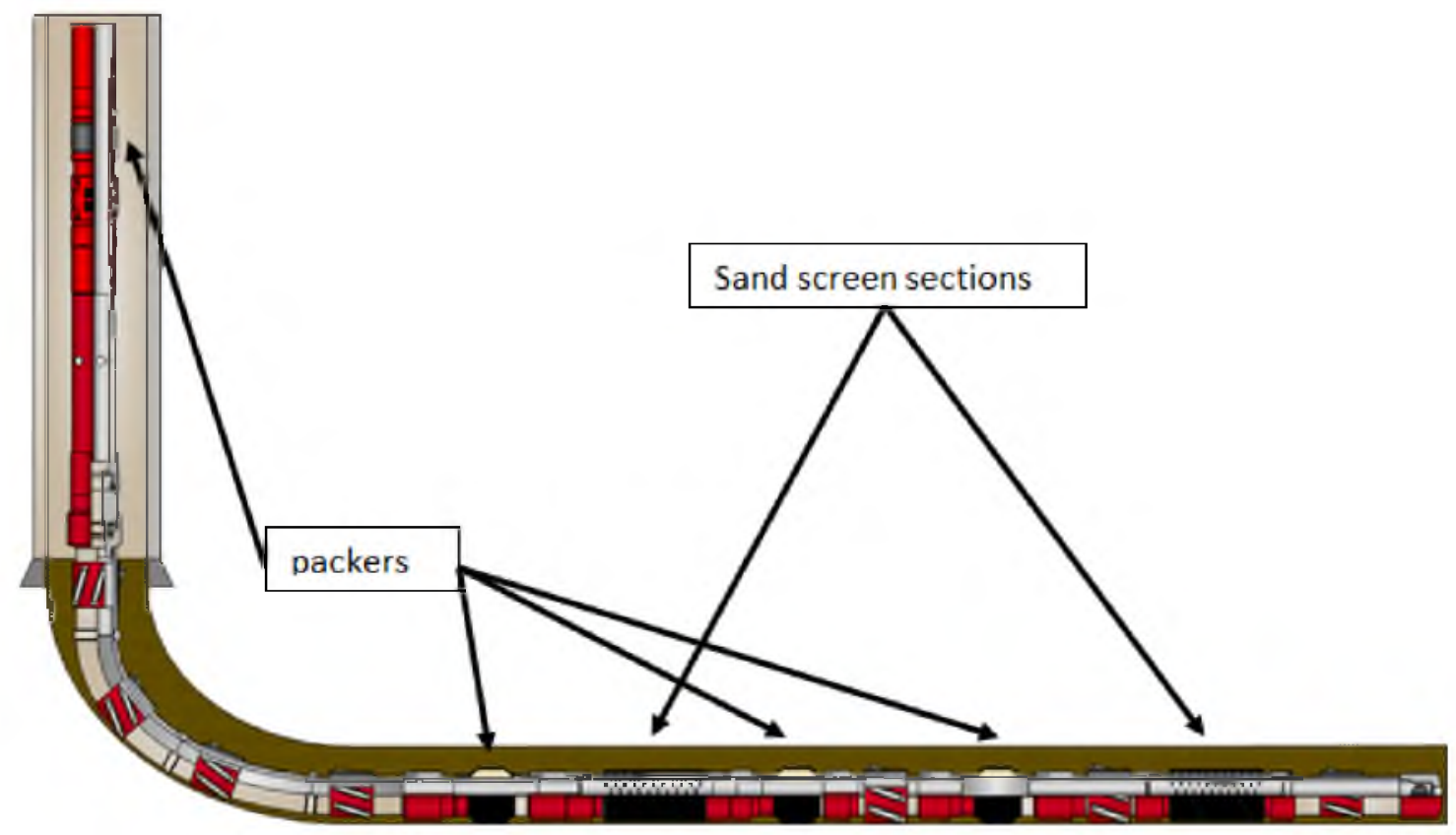

Figure 2: Completion Configuration with Packers and Screens

An example of artificial lift equipment (used to assist production) is gas lift equipment. An example of a gas lift mandrel is presented in Figure 3. 

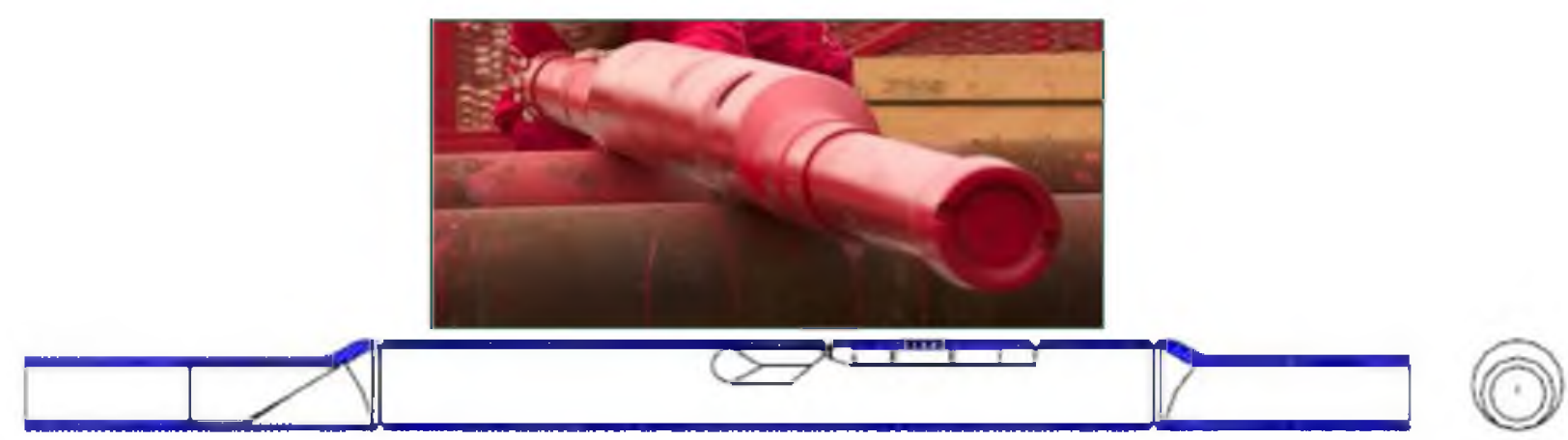

Figure 3: Example of a Gas Lift Mandrel

An example of wellhead equipment is the valve block that is presented in Figure 4. This is part of a Christmas tree that is used to direct and control flow at the wellhead.

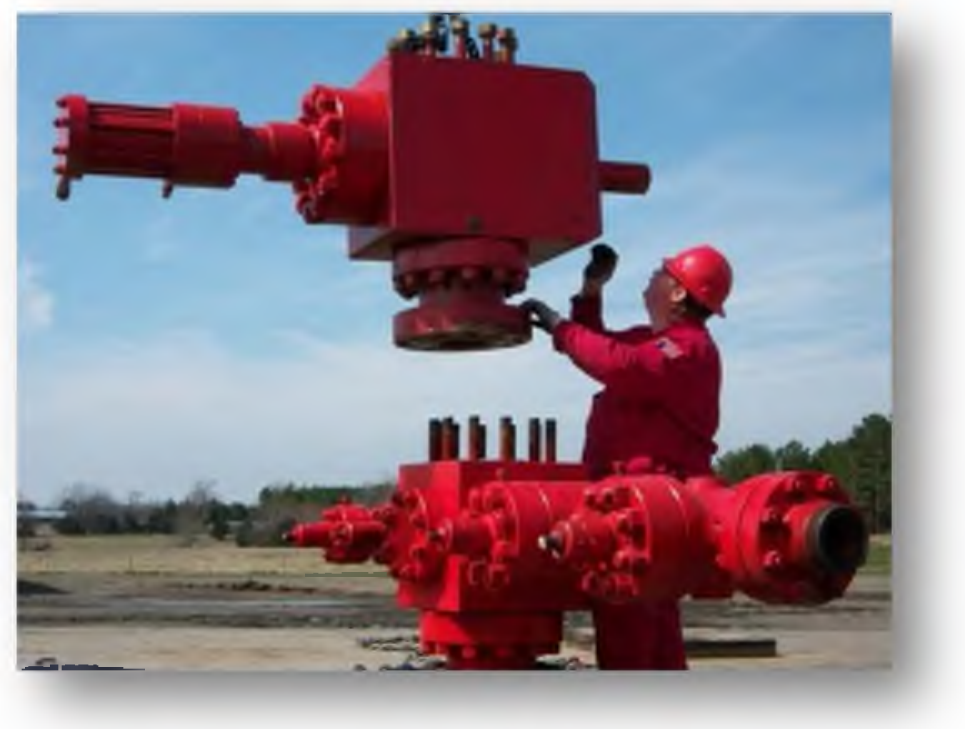

Figure 4: Example of a Valve Block (being lowered onto position as part of the wellhead)

\section{Oil and Gas Specifications}

The specifications that govern the nickel base alloy use are written and maintained through API (American Petroleum Institute) and NACE International and their ISO corresponding documents. From a metallurgical perspective, the main standards are NACE MR0175/ISO $15156^{2}$, API $6 \mathrm{~A} 718^{3}$ and API $5 \mathrm{CRA}^{4}$.

The last publication of NACE MR0175/ISO 15156 was in 2009 and the next version is being finalized now and going through the balloting/publication process for publication at the end of 2014 or beginning of 2015 . Between these 5 year revision cycles, updates with the positive ballot results are published. The document lists restrictions on processing and use limits. Table 3 lists some examples of the environmental limits of application and condition for 718 


\begin{tabular}{|c|c|c|c|}
\hline \multicolumn{4}{|c|}{ Table 3: 718 Limitations in NACE MR0175/ISO 15156 (2009) } \\
\hline \multirow{2}{*}{ Condition $^{1}$} & $\begin{array}{c}\text { Maximum } \\
\text { Temperature }{ }^{\circ} \mathrm{C}\left({ }^{\circ} \mathrm{F}\right)\end{array}$ & $\begin{array}{c}\text { Maximum H2S partial } \\
\text { pressure } \mathrm{kPa}(\mathrm{psi})\end{array}$ & Other \\
\hline \multirow{2}{*}{$\begin{array}{c}\text { May be cast or } \\
\text { wrought }\end{array}$} & $232(450)$ & $200(30)$ & No elemental sulfur \\
\cline { 2 - 4 } & $204(400)$ & $1400(200)$ & No elemental sulfur \\
\cline { 2 - 4 } & $149(300)$ & $2700(400)$ & No elemental sulfur \\
\hline Note 1: maximum hardness restrictions; 40 HRC for the solution annealed \& aged \\
\hline
\end{tabular}

The primary role of NACE MR0175/ISO 15156 is to prevent environmental cracking; this includes hydrogen embrittlement, chloride stress corrosion cracking and sulfide stress corrosion cracking. The API 6A718 was written to augment existing requirements in other API specifications to further specify and limit composition, processing and microstructure to prevent embrittlement associated with the presence of unacceptable levels of deleterious phases. The primary goal of the document has been centered on limiting the presence of delta phase. An API Workgroup for $6 \mathrm{~A} 718$ has been working on extending microstructural requirements to other precipitation hardening nickel base alloys but the work is still within committee.

The API 5CRA was written to define the technical delivery conditions for corrosion-resistant alloy seamless tubulars for casing, tubing, coupling stock and accessory equipment at two product specification levels (PSL 1 and PSL 2). The nickel base alloys are defined as group 4 in this standard. The standard lists mechanical property, ductility and impact toughness requirements for all grades. The current listing of the group 4 alloys with the available minimum yield strengths are presented in Table 4.

\begin{tabular}{|c|c|c|}
\hline & Table 4: Group 4 Alloys and Strength Level Grades in API 5CRA \\
\hline Category & Nominal Cr-Ni-Mo composition & Minimum yield strength grades, MPa (ksi) \\
\hline $21-42-3$ & $21 \% \mathrm{Cr}-42 \% \mathrm{Ni}-3 \% \mathrm{Mo}$ & $793(110), 896(125), 1000(140)$ \\
\hline $22-50-7$ & $22 \% \mathrm{Cr}-50 \% \mathrm{Ni}-7 \% \mathrm{Mo}$ & $793(110), 896(125), 1000(140)$ \\
\hline $25-50-6$ & $25 \% \mathrm{Cr}-56 \% \mathrm{Ni}-6 \% \mathrm{Mo}$ & $793(110), 896(125), 1000(140)$ \\
\hline $20-54-9$ & $20 \% \mathrm{Cr}-50 \% \mathrm{Ni}-9 \% \mathrm{Mo}$ & $793(110), 896(125), 1000(140)$ \\
\hline $22-52-11$ & $21.5 \% \mathrm{Cr}-52 \% \mathrm{Ni}-11 \% \mathrm{Mo}$ & $793(110), 896(125), 1000(140)$ \\
\hline $15-60-16$ & $15 \% \mathrm{Cr}-60 \% \mathrm{Ni}-16 \% \mathrm{Mo}$ & $793(110), 896(125), 1000(140)$ \\
\hline
\end{tabular}

\section{Failure Mechanisms}

For drilling equipment, we have found that the predominant failure mechanism is fatigue related, often corrosion fatigue. Other mechanisms include tensile overload, stress corrosion cracking and hydrogen embrittlement.

An example of a 718 alloy fatigue failure in a rotary steering mechanism a few years ago prompted an investigation to understand the root failure cause, correct the cause and optimize the fatigue life of the 718 alloy. The fatigue crack initiated at a stress riser in the highest loaded section of the tool; a photograph of the fractured section is presented in Figure 5. A high magnification photomicrograph of the surface using scanning electron microscopy is presented in Figure 6. The fatigue striations were clearly evident in the SEM (Scanning Electron Microscopy) photograph. 


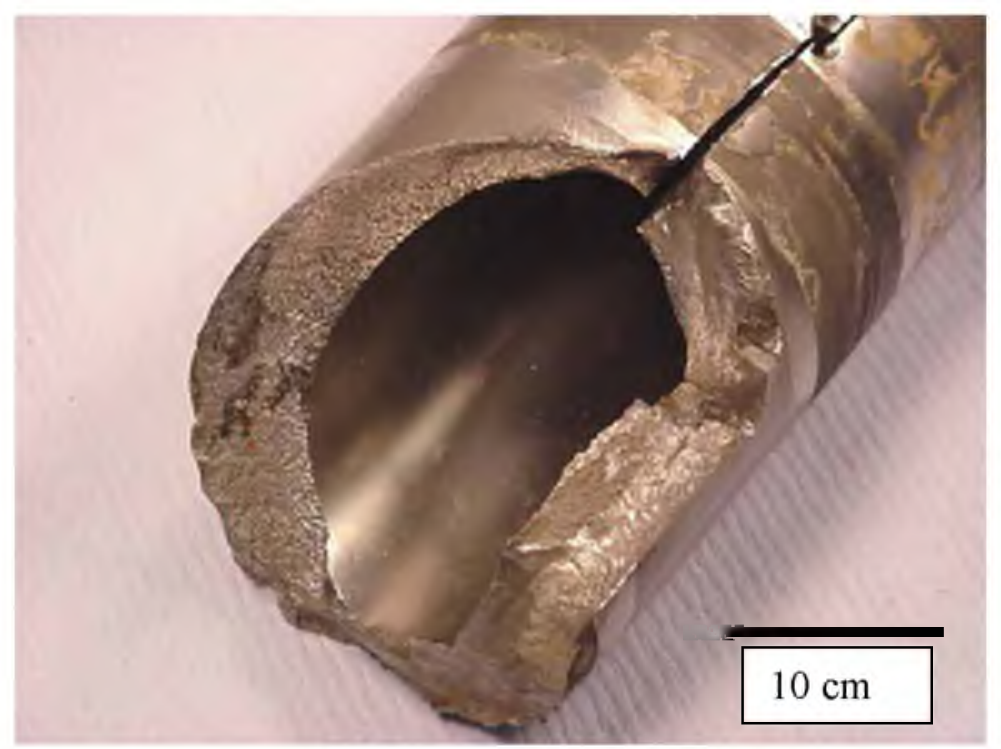

Figure 5: Fracture Surface of a Rotary Steering Tool

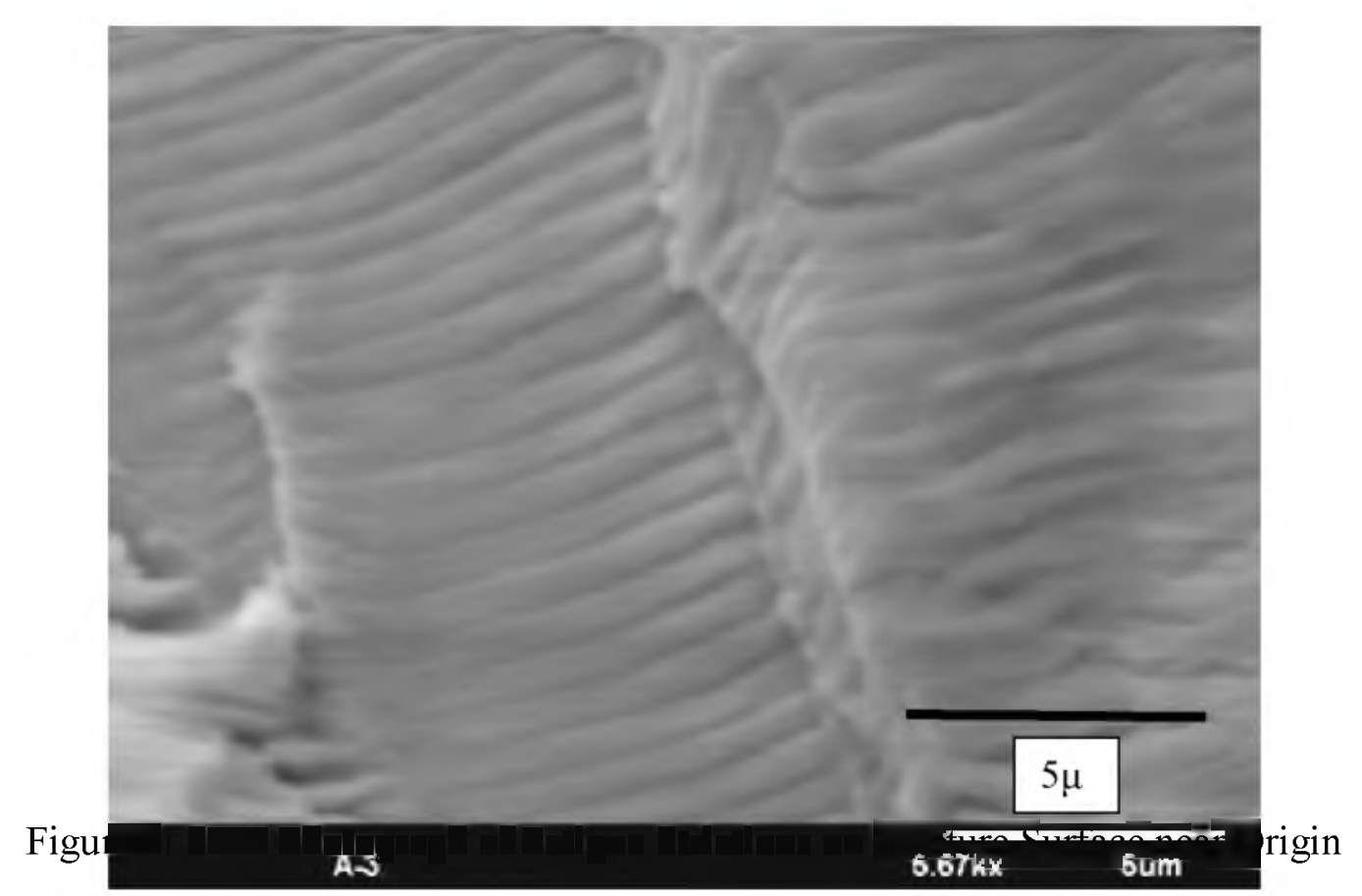

Part of the work to optimize the fatigue characteristics of 718 and investigate surface treatments to impart beneficial compressive stresses was presented last year ${ }^{5}$. The result was a modest improvement in fatigue life through process control and grain size refinement. The relative effectiveness of several surface treatments was quantified.

Fatigue life can also be increased through heat treatment. Kawagoshi et $\mathrm{al}^{6}$ is one of the more recent publications that demonstrated the advantage in two step aging compared with peak aging in 718 alloy. The heat treatments compared were a peak aged 10 hours at $720^{\circ} \mathrm{C}$ versus 8 hours at $720^{\circ}$ with a furnace cool to $621^{\circ} \mathrm{C}$ and held for 8 hours. These authors demonstrated significant increases in fatigue life at room temperature and at $500^{\circ} \mathrm{C}$.

For completion and production equipment we see a variety of mechanisms, prevalent are tensile overload, stress corrosion cracking, pitting and crevice corrosion, erosion corrosion, sulfide 
stress corrosion cracking and hydrogen embrittlement. Most of these mechanisms have been well understood for a long time and there are few mysteries regarding cause and effect. There is an exception; there have been several failures in precipitation hardened nickel base alloys over the last few years that have been attributed to hydrogen embrittlement but the hydrogen source has not been positively identified ${ }^{7,8}$. Also, the factors that determine the relative susceptibility of the nickel base alloy have not been identified.

Some work has already been published ${ }^{9}$ from investigations on hydrogen embrittlement in precipitation hardened nickel base alloys. The initial results indicate that the $625+$ alloy is much more susceptible to hydrogen embrittlement regardless of strength level when compared with lessor alloyed precipitation hardened alloys such as 718,925 and 935. A version of 718 with a lower strength level performed worse than a high strength level in this investigation and this was attributed to a greater amount of grain boundary precipitates (delta phase).

The latest on this hydrogen embrittlement mechanism is a JIP entitled "Operators Initiative for Assessing Hydrogen Stress Cracking of PH Nickel Alloys" that is headed by Thierry Cassagne of Total EP (the author is a member). The JIP will investigate hydrogen embrittlement using slow strain rate testing (SSRT) with fracture surface quantitative stereology. The initial variables being assessed are strength level, iron content and grain boundary precipitates.

\section{Recent Challenges and Future Direction}

There are three challenges or areas that need work for the Oil \& Gas Industry. The $1^{\text {st }}$ pertains to the need for higher strength nickel base alloys that will meet the increasing needs for developing HPHT fields. The needs are already trickling down into our drilling, completion and production business sectors. The drilling segment has a need for a $1140 \mathrm{MPa}(165 \mathrm{ksi})$ yield strength product today and could use a $1240 \mathrm{MPa}(180 \mathrm{ksi})$ product if it were available. The materials need to be tough, fatigue resistant and exhibit sufficient resistance to corrosion and environmental cracking including hydrogen embrittlement. The completions and production segments need 965 - $1035 \mathrm{MPa}(140-150 \mathrm{ksi})$ yield strength now with good corrosion resistance and environmental cracking resistance including hydrogen embrittlement.

The $2^{\text {nd }}$ challenge pertains to economics. There is room for work both in reducing wasted metal through machining stocks/boring and more cost effective alloys for less challenging applications. On the wasted metal, there has been work on cold \& warm forming both solid solution and precipitation hardened nickel base alloys to better ID/OD relationships. This needs more proving out but is promising. On the more cost effective alloys, our industry transitions from the low end stainless steels such as $13 \% \mathrm{Cr}$ and $13 \% \mathrm{Cr}-5 \% \mathrm{Ni}-2 \% \mathrm{Mo}$ alloys over to the $3 \%$ Mo containing nickel base alloys once the $\mathrm{H}_{2} \mathrm{~S}$ partial pressure exceed very low limit such as $10 \mathrm{kPa}(1.5 \mathrm{psi})$. There would be a huge market for a lower cost nickel base alloy that had the following characteristics: yield strength at or above $760 \mathrm{MPa}(110 \mathrm{ksi})$, corrosion resistance equal to a $13 \mathrm{Cr}-5 \mathrm{Ni}-2 \mathrm{Mo}$ stainless steel and cracking resistance in $\mathrm{H}_{2} \mathrm{~S}$ levels up to about $200 \mathrm{kPa}$ (30 psi) with chlorides.

The last challenge is better understanding the circumstances in our applications where we have hydrogen sources and the variables that affect the resistance to hydrogen embrittlement in the precipitation hardened nickel base alloys. 


\section{References}

1) NACE Publication 1F196, "Survey of CRA Tubular Usage", NACE International, March, 1996, Houston, Texas, 3-4.

2) NACE MR0175/ISO 15156-3 "Petroleum and natural gas industries-Materials for use in H2S-containing Environments in oil and gas production - Part 3: Cracking-resistant CRAs (corrosion-resistant alloys) and other alloys", ANSI/NACE, 2009, 10-48.

3) American Petroleum Institute, 2010. API 6A-718 Specification of Nickel Base Alloy 718 (UNS N07718) for Oil and Gas Drilling and Production Equipment - Upstream Segment' 2nd Edition. Washington DC, 1-18.

4) American Petroleum Institute., 2010. API 5CRA Specification for Corrosion Resistant Alloy Seamless Tubes for Use as Casing, Tubing and Coupling Stock 1st Edition. Washington DC, 1-87.

5) R. Badrak, S. Kolesov, C. Lawson, D. Minett-Smith 2013: "Fatigue and 718 Nickel Base Alloy", EUROCORR 2013, September 2013, Estoril, Portugal, 1-9.

6) N. Kawagoishi, Initiation and Propagation Behavior of a Fatigue Crack of Alloy 718", International Journal of Modern Physics B, 25 (15) (2010), 2857-2862

7) T. Cassagne, M. Bonis, D. Hillis, C. Duret 2008: "Understanding field failures of alloy 718 forging materials in HP/HT wells", EUROCORR 2008, September 2008, Edinburgh UK, 1-13.

8) P. Nice et al 2014: "Hydrogen Embrittlement Failure of a Precipitation Hardened Nickel Alloy Subsurface Safety Valve Component Installed in a North Sea Seawater Injection Well", NACE CORROSION 2014, paper 3892, March, 2014, San Antonio, Texas, 1-16.

9) L. Foroni and C. Malara 2014: "Hydrogen Embrittlement Susceptibility of Precipitation Hardened Ni Alloys", NACE CORROSION 2014, paper 3948, March, 2014, San Antonio, Texas, 1-15. 